\title{
A STUDY OF CLUSTER BEHAVIORAL ABNORMALITIES IN DOWN SYNDROME
}

RANJAN BHATTACHARYYA, DEBASISH SANYAL, KRISHNA ROY, SANJAY SAHA ${ }^{1}$

\section{ABSTRACT}

BACKGROUND: The behavioral phenotype in Down syndrome follows a characteristic pattern. AIMS: To find the incidence of behavioral abnormalities in Down syndrome, to compare these findings with other causes of intellectual disability and normal population and to cluster these abnormalities. SETTINGS: One hundred forty mentally challenged people attending at tertiary care set up and from various non-governmental organizations were included in the study. Patients from both rural and urban set up participated in the study. The age-matched group from normal population was also studied for comparison. DESIGN: The study design is a cross-sectional survey done independently by four observers. MATERIALS AND METHODS: A semi-structured proforma for demographic profile has been used. The behavioral abnormalities are assessed by using DASH II (Diagnostic Assessment for the Severely Handicapped second modified version) scale. STATISTICAL ANALYSIS: Demographic comparison has been done by analysis of variance. Correlation matrix has been run to identify correlation between individual items. Principal component analysis has been used for grouping the behavioral pattern. RESULTS: Behavioral abnormalities as expected are more common in people having intellectual disability than the normal population. The Down syndrome group unlike other causes of intellectual disability shows higher scores in Stereotypy. Impulse control and Mania subscales. Factor analysis yields five characteristic factor structures, namely, hyperactive-impulsive, biological functions, affective, neurotic and organic-pervasive developmental disorder clusters. CONCLUSIONS: Contrary to the conventional belief of docile-fun and music loving prototype, individuals diagnosed with Down syndrome show clusters of behavioral abnormalities and management can vary depending on these target symptoms.

Key words: Behavioral phenotype, DASH II scale, Down syndrome, intellectual disability DOI: 10.4103/0019-5359.49232

\section{INTRODUCTION}

The formal story began in 1866, when a

Departments of Psychiatry, Calcutta National Medical College, and ${ }^{1}$ Community Medicine, AllH \& PH, India

\section{Correspondence:}

Dr. Ranjan Bhattacharyya,

29, Anandasree, Garia, Kolkata-700 084, India.

E-mail: rankholders06@yahoo.co.in physician, Dr John Langdon Down, published an essay in England in which he described a set of children with common features, who were distinct from other children with intellectual disability. ${ }^{[1]}$ Down syndrome is the most common genetic (chromosomal) intellectual disability, occurring in from 1 of 700 to 1 of 1000 live births. ${ }^{[2]}$ Various 
researchers over the years had noted a correlation between physical anomalies in a group of children grouped together as "hyperactive". ${ }^{[3]}$ During the past few decades, research has begun to converge on a specific behavioral phenotype associated with Down syndrome. The factors responsible for the challenging behaviors include characteristics associated with the Down syndrome behavioral phenotype, increased incidence of illness and sleep disorders, and the manner in which individuals in their environment respond to their behaviors. ${ }^{[4]}$

Individuals with Down syndrome have frequently been described as having charming personalities in accordance with a positive Down syndrome personality stereotype. ${ }^{[5]}$ Older children and young adults with Down syndrome have been described as having primarily positive mood and more predictable in their behavior. ${ }^{[6]}$ However, the behavior characteristics of the adults with Down syndrome said to remain constant in the younger and older age groups by the researchers. ${ }^{[7]}$

Many children with Down syndrome also show lower level of task persistence and higher level of off-task behavior, interfering with task completion. ${ }^{[8]}$

The topic of emotional problem in intellectually disabled individuals has received considerable attention among the Mental Health professionals..$^{\left[{ }^{[9]}\right.}$ An estimate that mental health problem is five times higher in intellectually disabled than general population is quite a conservative one. ${ }^{[10]}$ The various recognized syndromes involving a genetic disorder have now been isolated and many have behavioral epiphenomena. While assessing the children with global developmental delay, it is also vital not to miss conditions that are exacerbating it or are treatable. For example, hypothyroidism is present in approximately $15 \%$ to $20 \%$ children with Down syndrome, which can influence the intellectual and behavioral profile in this population. ${ }^{[11]}$

The need for the present study is to cluster the behavioral problems in Down syndrome, especially those showing definitive karyotyping abnormality, which will help to guide research for its neurobiological correlates. Such clustering will also help to guide various professionals to establish a comprehensive therapeutic and rehabilitative approach or providing targeted interventions accordingly. The specific objectives of this study were to find common behavioral abnormalities in Down syndrome; to correlate the behavioral abnormalities in between the individual items of Diagnostic Assessment for the Severely Handicapped (DASH) scale and correlate these with intelligence quotient (I.Q.)

\section{MATERIALS AND METHODS}

The subjects for this study were 70 karyotype confirmed Down syndrome cases, 70 nonDown syndrome causes of intellectual disability and 70 age-matched healthy controls from general population, which henceforth will be described as "cases," "comparison" and "normal" group, respectively. This study is a cross-sectional survey done independently by four qualified trained researchers. The researchers were blinded as they were not aware of the karyotyping report during 
assessment of behavioral profile. The study population comprised subjects with Down syndrome who were attending tertiary health care facility as well as those from various organizations caring for intellectually disabled people. The study had been carried out for one and half years between February 2007 and August 2008. The karyotyping-proved Down syndrome cases as well as other causes of intellectual disability (karyotyping negative) who meet all the inclusion criteria and none of the exclusion criterion, had been included in the study and their parents interviewed to provide the details of the clinical profile and the demographic data.

The study has been designed to cluster the behavioral abnormalities seen in the Down syndrome group and to compare these findings with the other causes of intellectual disability and age-matched normal population group. Some of the earlier scales to develop the behavioral abnormalities in this population are as follows:

1. Reiss Screen ${ }^{[12]}$

2. Psychopathology Instrument for Mentally Retarded Adults (PIMRA) ${ }^{[13]}$

3. Aberrant Behavior Checklist $(\mathrm{ABC})^{[14]}$

The Aberrant Behavior Checklist $(\mathrm{ABC})$ is a 58-item rating scale, whereas DASH scale comprises 97 items divided into 13 major disorders. The DASH scale was selected for the present study, as it will provide more flexibility for inclusion of more number of behavioral variations found in people having intellectual disability. Moreover, its content validity was established by deriving disorder subscales and individual items from Diagnostic and Statistical Manual of Diseases (DSM)-III-R
(American Psychiatric Association, 1987) and previous studies of this population. ${ }^{[15]}$

The items of DASH scale focus on observable behaviors and are used for screening purposes to assess the frequency, duration and severity of psychiatric symptoms related to the DSM criteria. Each dimension provided for rating on one of three levels scored 0,1 or 2 . The usual time required to apply this scale averages 60 to 90 minutes and less as the rater becomes accustomed to using this scale. In order to avoid complexity, only the frequency of this scale item has been analyzed. The inter-rater reliability of the DASH mood subscale was found to be 0.92 and the test-retest reliability of subscale was reported to be 0.88 . The depression subscale of the DASH displayed convergent validity of 0.75 with the scale $A B C .^{[14]}$

The mood subscale items include both atypical symptoms and behavioral equivalents. The mania rating scale items of the DASH II screening instrument for individuals with learning disabilities (restless or agitated, decreased need for sleep, irritable, easily distracted, extremely happy or cheerful for no obvious reason, talks loudly and quickly) show good internal correlation and specificity with the mania DSM-IV. ${ }^{[16]}$

Somatic symptoms and their behavioral correlate, e.g., changes in energy and activity levels, sleep and appetite changes and social withdrawal is suggestive of affective disorders. ${ }^{[17]}$ Regression to increased dependency, psychomotor agitation, increased irritability, worsening of already existing behavioral problems, aggressive and selfinjurious behavior, reduced communication 
and social isolation are more common among people with intellectual disability. ${ }^{[16]}$ The DASH scale was used to assess 506 intellectually disabled individuals (247 female and 259 male). Elimination and pervasive developmental disorders were found to be most frequent and self-injurious behavior disorders were most severe. The majority of the symptoms had been evident for at least 1 year. ${ }^{[18]}$ The emotional problems in intellectually disabled individuals have found to be more severe and pronounced than the problems observed in general population.

The DASH II scale differs from previous instruments on several aspects. First, its content validity was established by deriving disorder subscales and individual items from DSM-III-R (American Psychiatric Association, 1987) and previous studies of this population. High levels of depressed mood are associated with self and informant-related measures of poor social skills and low levels of social support in those with learning disabilities. Borthwick-Duffy SA (1994) recorded that $27 \%$ of individuals with intellectual disability had anxiety disorder. ${ }^{[19]}$ The comorbidity with other psychiatric illness, e.g., depression is also common. ${ }^{[20]}$

The mean IQ of children with Down syndrome averages about 45 (range, 25-70). The IQ level tends to remain stable during middle childhood and influenced by quality of care provided. Mosaicism (mixture of trisomic and normal cell lines) can be found in $2 \%$ to $3 \%$ patients with Down syndrome, and they tend to achieve somewhat higher intellectual development and particularly perform better in verbal and visuospatial skills. ${ }^{[21]}$ The older children and young adults with Down syndrome are described as primarily positive mood and predictable in their behavior but less active and persistent and more distractible than older children as well. ${ }^{[6]}$

\section{RESULTS}

The three groups are represented uniformly as far as the population distribution is concerned. While age of Down syndrome cases ranged from 3 to 37 years, that of other the group, 3 to 39 years and that of control, 3 to 31 years. The sex difference in between the groups has not found to be statistically significant $\left(X^{2}=\right.$ 5.833, $d f=2, P=0.054)$. The average paternal and maternal age at the time of childbirth in Down syndrome are 35.76 and 31.16 years, respectively, which corroborates the earlier findings that the incidence of Down syndrome increases with both increase in paternal and maternal age [Table 1]. The maternal age of marriage and income are other significant demographic variables $(P<0.000)$. The only mosaic variety of Down syndrome in this study had total IQ of 64 , with lower maternal age of childbirth (25 years) and less behavioral abnormalities. About $22.84 \%$ patients with Down syndrome also had hypothyroidism, and the only translocation variety case also had relatively higher total IQ (62) and borne by relatively younger mother (26 years). Among the 13 major subscales in DASH scale, the stereotypy ( $n=44,62.9 \%)$, impulse control $(\mathrm{n}=36,51.4 \%)$ and mania subscales $(\mathrm{n}=$ $31,44.3 \%$ ) are present in significantly higher frequencies in the Down syndrome group, whereas organic subscale ( $n=48,68.6 \%$ ) and impulse control disorder subscales ( $\mathrm{n}$ $=42,60.0 \%$ ) more commonly present in 
Table 1: Descriptive and inferential statistical summary of demographic profile

\begin{tabular}{|c|c|c|c|c|c|c|}
\hline Demographic variables & Group & $N$ & Mean & $S D$ & $F$ & Significance $(P)$ \\
\hline \multirow[t]{3}{*}{ Age } & DS & 70 & $16.30^{1}$ & 10.288 & \multirow[t]{3}{*}{1.771} & \multirow[t]{3}{*}{0.173} \\
\hline & COMP & 70 & $14.93^{2}$ & 8.030 & & \\
\hline & NOR & 70 & $13.61^{3}$ & 6.579 & & \\
\hline Paternal age at & DS & 70 & 35.76 & 7.264 & \multirow[t]{3}{*}{11.731} & \multirow[t]{3}{*}{$<0.001^{\star \star \star}$} \\
\hline \multirow[t]{2}{*}{ childbirth } & COMP & 70 & 32.51 & 4.886 & & \\
\hline & NOR & 70 & 31.50 & 3.446 & & \\
\hline Maternal age at & DS & 70 & 31.16 & 5.067 & \multirow[t]{3}{*}{22.066} & \multirow[t]{3}{*}{$<0.001^{* * *}$} \\
\hline \multirow[t]{2}{*}{ childbirth } & COMP & 70 & 26.59 & 4.356 & & \\
\hline & NOR & 70 & 27.14 & 3.816 & & \\
\hline \multirow[t]{3}{*}{ Income } & DS & 70 & 3.06 & 1.020 & \multirow[t]{3}{*}{3.724} & \multirow[t]{3}{*}{$0.026^{\star}$} \\
\hline & COMP & 70 & 2.90 & 0.837 & & \\
\hline & NOR & 70 & 3.29 & 0.617 & & \\
\hline \multirow{3}{*}{$\begin{array}{l}\text { Maternal age of } \\
\text { marriage }\end{array}$} & DS & 70 & 28.60 & 4.308 & \multirow[t]{3}{*}{74.373} & \multirow[t]{3}{*}{$<0.001^{\star \star *}$} \\
\hline & COMP & 70 & 22.64 & 3.750 & & \\
\hline & NOR & 70 & 22.09 & 2.048 & & \\
\hline \multirow[t]{3}{*}{ Birth order } & DS & 70 & 2.11 & 2.004 & \multirow[t]{3}{*}{3.010} & \multirow[t]{3}{*}{0.051} \\
\hline & COMP & 70 & 1.57 & 0.894 & & \\
\hline & NOR & 70 & 1.66 & 1.062 & & \\
\hline
\end{tabular}

${ }^{\star} P<0.05,{ }^{\star \star \star} P<0.001$, N.S. $=$ Not significant, 1. Range=2.5-37.0, 2. Range=2.0-39.0, 3. Range=3.0-31.0, DS= Down syndrome cases. $\mathrm{COMP}=$ other causes of intellectual disability, $\mathrm{NOR}=$ Age matched normal control group

Table 2: Frequencies of DASH II subscales in the three groups studied

\begin{tabular}{|c|c|c|c|c|c|c|}
\hline \multirow[t]{2}{*}{ Item } & \multirow{2}{*}{$\begin{array}{c}D S \\
N\end{array}$} & \multicolumn{3}{|c|}{ Comparison } & \multirow{2}{*}{$\begin{array}{c}\text { Normal } \\
N\end{array}$} & \multirow[t]{2}{*}{$\%$} \\
\hline & & $\%$ & $N$ & $\%$ & & \\
\hline Anxiety & 9 & 12.9 & 2 & 2.9 & 0 & 0.0 \\
\hline Depression & 17 & 24.3 & 8 & 11.4 & 3 & 4.3 \\
\hline Mania & 31 & $44.3^{*}$ & 7 & 10.0 & 2 & 2.9 \\
\hline PDD & 28 & 40.0 & 23 & 32.9 & 0 & 0.0 \\
\hline Schizophrenia & 5 & 7.1 & 3 & 4.3 & 0 & 0.0 \\
\hline Stereotypy & 44 & $62.9^{*}$ & 41 & 58.6 & 1 & 1.4 \\
\hline Sib & 6 & 8.6 & 28 & 40.0 & 0 & 0.0 \\
\hline Elimination & 15 & 21.4 & 16 & 22.9 & 1 & 1.4 \\
\hline Eating & 18 & 25.7 & 16 & 22.9 & 2 & 2.9 \\
\hline Sleep & 70 & 28.6 & 18 & 25.7 & 3 & 4.3 \\
\hline Sexual & 15 & 25.7 & 18 & 25.7 & 0 & 0.0 \\
\hline Organic & 26 , & 37.1 & 48 & $68.6^{*}$ & 0 & 0.0 \\
\hline Impulse & 36 & $51.4^{*}$ & 42 & $60.0^{*}$ & 7 & 10.0 \\
\hline
\end{tabular}

*Highest frequencies observed in the group, DS= Down syndrome cases, PDD= Pervasive developmental disorder, $\mathrm{SIB}=$ Self-injurious behaviour.

comparison group [Tables 2 and 3]. The least frequent anomalies are schizophrenia and anxiety disorders in the Down syndrome group. Overall the behavioral abnormalities as evident from the scoring in the DASH scale are more common in other non-Down syndrome cases of intellectual disability group than in Down syndrome group. The correlation matrix shows positive correlations between the Anxiety and Elimination; Pervasive developmental disorder (PDD) and organic; Self-injurious behavior and Impulse control disorder with Sexual
Table 3: Frequency of various items of dash II scale in Down syndrome

\begin{tabular}{lcc}
\hline Item name & Mean & $S D$ \\
\hline Anxiety & 0.13 & 0.337 \\
Depression & 0.27 & 0.509 \\
Mania & 0.54 & 0.674 \\
PDD & 0.41 & 0.525 \\
Schizophrenia & 0.07 & 0.259 \\
Stereotypy & 0.80 & 0.714 \\
Sib & 0.14 & 0.460 \\
Elimination & 0.26 & 0.530 \\
Eating & 0.30 & 0.548 \\
Sleep & 0.34 & 0.587 \\
Sexual & 0.30 & 0.548 \\
Organic & 0.39 & 0.519 \\
Impulse & 0.59 & 0.625 \\
\hline
\end{tabular}

$\mathrm{PDD}=$ Pervasive developmental disorder, $\mathrm{SIB}=$ Self injurious behaviour, $\mathrm{SD}=$ Standard deviation 
disorder; Sleep and eating disorder items. Inverse relationship (negative correlation) has been found between depression and mania subscales of this instrument. The Mania item of DASH scale is negatively correlated with Depressive item; Self-injurious behavior is correlated with Sexual and Impulse control disorder. Eating item of the DASH scale is positively related to sleep disorder item. The organic subscale is positively correlated with impulse control disorder subscale [Table 4]. By computing factor analysis (principal component analysis with varimax rotation) of individual items of DASH scale with the help of SPSS software version 15 , following five clusters emerged. (1) Hyperactive-Impulsive, (2) Biological functions, (3) Affective, (4) Neurotic and (5) Organic-PDD clusters [Tables 5 and 6]. The stereotypy, impulse control disorder and Mania subscales scored significant higher rating in the Down syndrome group.

\section{DISCUSSION}

Nyhan introduced the term "behavioral phenotype" to describe externally observable behavior so characteristic of children with genetic disorders that its presence suggests the underlying genetic condition. ${ }^{[22]}$ The result of this study establishes a distinct behavioral phenotype in Down syndrome. At the same time, it challenges traditional positive fun and music loving characteristics reported to be associated with Down syndrome. The behavioral phenotype is a characteristic pattern of motor, cognitive, linguistic and social abnormalities that is consistently associated with a biological or neurodevelopmental disorder. This does not mean that the behavior is present in all instances but that the probability of its occurrence is increased. The previous studies confirm there to be a behavior phenotype among adults with Down syndrome. The reasons for this (e.g., genetic/ psychological/social) require further research. ${ }^{[7]}$

The presence of stereotypy, impulse control and mania subscales in higher percentages in the Down syndrome group possibly suggests a common thread of involvement of disinhibition circuit, which requires further study to establish this hypothesis, especially correlating with functional neuroimaging (fMRI). ${ }^{[23]}$ The charming quality of mood is not

Table 4: Correlation matrix of items of DASH II scale in Down syndrome

\begin{tabular}{lcccccccccc}
\hline & $A N X$ & $D E P R$ & $M A N I A$ & $P D D$ & $S I B$ & $E L I M$ & $E A T$ & $S L E E P$ & $S E X$ & $I M P U L S E$ \\
\hline ANX & 1.000 & -0.037 & 0.262 & 0.104 & 0.067 & $0.299^{*}$ & -0.055 & -0.006 & 0.102 & 0.050 \\
DEPR & -0.037 & 1.000 & -0.309 & -0.047 & 0.142 & -0.048 & 0.276 & 0.121 & 0.016 & 0.222 \\
MANIA & 0.262 & -0.309 & 1.000 & 0.011 & 0.073 & 0.090 & 0.102 & 0.219 & 0.102 & 0.335 \\
PDD & 0.104 & -0.047 & 0.011 & 1.000 & 0.172 & 0.028 & -0.086 & 0.003 & 0.116 & 0.001 \\
SIB & 0.067 & 0.142 & 0.073 & 0.172 & 1.000 & 0.085 & 0.000 & 0.031 & $0.518^{*}$ & $0.411^{*}$ \\
ELIM & $0.299^{*}$ & -0.048 & 0.090 & 0.028 & 0.085 & 1.000 & -0.020 & 0.132 & 0.130 & 0.064 \\
EAT & -0.055 & 0.276 & 0.102 & -0.086 & 0.000 & -0.020 & 1.000 & $0.397^{*}$ & 0.034 & 0.283 \\
SLEEP & -0.006 & 0.121 & 0.219 & 0.003 & 0.031 & 0.132 & $0.397^{*}$ & 1.000 & 0.036 & 0.274 \\
SEX & 0.102 & 0.016 & 0.102 & 0.116 & $0.518^{*}$ & 0.130 & 0.034 & 0.036 & 1.000 & $0.283^{*}$ \\
IMPULSE & 050 & 0.222 & 0.335 & 0.001 & $0.411^{*}$ & 0.064 & 283 & 0.274 & $0.283^{*}$ & 1.000 \\
\hline
\end{tabular}

*Significant correlation, ${ }^{\mathrm{a} O n l y}$ cases for which GROUP=Down syndrome are used in the analysis, ${ }^{\mathrm{b}}$ Determinant $=.075$,

Schizophrenia, Stereotypy and Organic subscales didn't show any correlation between them and therefore excluded from the table.

PDD and Organic subscales show positive correlation between each other (not shown in table; significance at the level of $1 \%$

$(P<0.01)$.

ANX = Anxiety disorder, DEPR=Depression, PDD= Pervasive developmental disorder, SCHIZ= Schizophrenia,

STEREO= Stereotypy, SIB= Self injurious behaviour, ELIM= Elimination disorder, EAT= Eating disorder, SEX= Sexual disorder 
Table 5: Rotated component matrix of DASH II scale in Down syndrome

\begin{tabular}{lccccc}
\hline \multicolumn{5}{c}{ Component } \\
\hline SIB & 1 & 2 & 3 & 4 & 5 \\
Sexual & 0.780 & & & & \\
Impulse & 0.724 & & & & \\
Sleep & 0.657 & & & & \\
Eating & & 0.798 & & & \\
Mania & & 0.772 & & & \\
Depression & & & 0.810 & & \\
Stereotypy & & & -0.634 & & \\
Elimination & & & & 0.758 & \\
Anxiety & & & & 0.729 & \\
Schizophrenia & & & & & 0.786 \\
Organic & & & & & 0.767 \\
PDD & & & & &
\end{tabular}

${ }^{*}$ Mania and Depression items are negatively correlated, $\mathrm{SIB}=$ Self-injurious behavior, $\mathrm{PDD}=$ Pervasive developmental disorder

alone present in this group for higher scoring in mania item. There is also a presence of sleep disturbances, becoming cranky or irritable and high distractibility; talking loudly adds to higher scoring of this subscale. The presence of organic subscale in other causes of intellectual disability warrants further investigation work up including structural neuroimaging to search for definite lesions in this group. The behavioral abnormalities in the Down syndrome group can be clustered by principal component analysis into five characteristic clusters, which can help future researchers to develop short behavioral screeners for Down syndrome and guide therapy (e.g., behavioral modification) accordingly.

However, the study has several limitations. (a) Sample size is small $(n=70)$ in each group. (b) Metabolic screening could not be performed because of administrative inconvenience; therefore, associated disorders of Inborn Error of Metabolism, if present, cannot be excluded. (c) A majority of
Table 6: Emerged 5 clusters in DASH II scale in Down syndrome

\begin{tabular}{|c|c|}
\hline Cluster & Component items \\
\hline Hyperactive-impulsive & $\begin{array}{l}\text { Self-injurious behavior } \\
\text { Sexual } \\
\text { Impulsive }\end{array}$ \\
\hline Biological functions & $\begin{array}{l}\text { Sleep disorder } \\
\text { Eating disorder }\end{array}$ \\
\hline Affective & $\begin{array}{l}\text { Mania } \\
\text { Depression* }\end{array}$ \\
\hline Neurotic & $\begin{array}{l}\text { Elimination } \\
\text { Anxiety }\end{array}$ \\
\hline Organic-PDD & $\begin{array}{l}\text { Organic } \\
\text { Pervasive developmental disorder }\end{array}$ \\
\hline
\end{tabular}

${ }^{\star}$ Negatively correlated, PDD = Pervasive developmental disorder

subjects are from the urban background. (d) Few cases were not included because of the absence of legal guardians to provide valid consent for participation in the study.

It will be preferable if a community-based study is conducted to know whether the findings of this study can be projected to the population at large. A closer liaison is required among the family members, pediatrician, psychiatrists, social workers and other trained professionals, including the nursing staffs to be familiar with Down syndrome behavioral phenotype.

The avenue for further research is wide open and there is a need for large-scale studies. The approach to a child with developmental delays/intellectual disability (DD/ID) includes the clinical history (including prenatal and birth histories), family history, physical and neurological examinations, emphasizing the examination for physical anomalies and behavioral abnormalities that might suggest a specific recognizable syndrome or diagnosis. After this clinical consultation, judicious use of laboratory tests, imaging and other consultant services can be performed with most patients in a cost-effective manner. 


\section{REFERENCES}

1. Chudley AE, Chodirker BN. Landmarks in genetics through philately: Down syndrome. Clin Genet 2003;63:268-72.

2. Hassold TJ, Jacobs PA. Trisomy in man. Ann Rev Genet 1984;18:69-97.

3. Jacklin CN, Maccoby EE, Halverson CF Jr. Minor physical anomalies and preschool behavior. J Pediatr Psychol 1980;5:199-205.

4. Feeley K, Jones E. Strategies to address challenging behaviour in young children with Down syndrome. Downs Syndr Res Pract 2008;12:153-63.

5. Gibbs MV, Thorpe JG. Personality stereotype of noninstitutionalized Down Syndrome children. Am J Mental Deficiency 1983;87:601-5.

6. Wishart JG, Willis DS, Cebula KR, Pitcairn TK. Collaborative learning: Comparison of outcomes for typically developing children and children with intellectual disabilities. Am J Mental Retard 2007;112:361-74.

7. Collacott RA, Cooper SA, Branford D, McGrother C. Behaviour phenotype for Down's syndrome. $\mathrm{Br}$ J Psychiatry 1998;172:85-9.

8. Mcgrath J, El-Saadi O, Grim V, Cardy S, Chapple B, Chant D, et al. Minor Physical anomalies and quantitative measures of the head and face in patients with psychosis. Arch Gen Psychiatry 2002;59:459-64.

9. Kessler RJ. Electroconvulsive therapy for affective disorders in persons with mental retardation. Psychiatr Quart 2004;75:99-104.

10. Rutter M, Tizard J, Yule W, Graham P, Whitmore K. Research report: Isle of Wright studies, 19641974. Psychol Med 1976;6:313-32.

11. Carroll KN, Arbogast PG, Dudley JA, Cooper WO. Increase in incidence of medically treated thyroid disease in children with Down Syndrome after rerelease of American Academy of Pediatrics Health Supervision guidelines. Pediatrics 2008;122:493-8.

12. Sturmey P, Bertman LJ. Validity of the Reiss screen for maladaptive behavior. Am J Mental Retard 1994;99:201-6.

13. Linaker O. DSM-III diagnoses compared with factor structure of the psychopathology instrument for mentally retarded adults (PIMRA), in an institutionalized, mostly severely retarded population. Res Dev Disabil 1991;12:143-53.

14. Aman MG, Burrow WH, Wolford PL. The Aberrant Behavior Checklist-Community: factor validity and effect of subject variables for adults in group homes. Am J Mental Retard 1995;100:283-92.

15. Karabekiroglu K, Aman MG. Validity of the aberrant behavior checklist in a clinical sample of toddlers. Child Psychiatry Hum Dev 2009;40: 99-110.

16. Matson JL, Smiroldo BB. Validity of the mania Subscale of the Diagnostic Assessment for the severely handicapped-II (DASH-II). Res Dev Disabil 1997;18:221-5.

17. Gau SS, Chiu YN, Soong WT, Lee MB. Parental characteristics, parenting style, and behavioral problems among chinese children with Down syndrome, their siblings and controls in Taiwan. J Formosan Med Assoc 2008;107:693-703.

18. Matson JL, Gardner WI, Coe DA, Sovner R. A scale for evaluating emotional disorder in severely and profoundly mentally retarded persons, DASH scale. Br J Psychiatry 1991;159:404-9.

19. Borthwick-Duffy SA. Epidemiology and prevalence of psychopathology in people with mental retardation. J Consulting Clin Psychol 1994;62: 17-27.

20. Dykens EM. Psychiatric and behavioral disorders in persons with Down syndrome. Ment Retard Dev Disabil Res Rev 2007;13:272-8.

21. Baddeley A, Jarrold C. Working memory and Down syndrome. J Intellect Disabil Res 2007;51:925-31.

22. Nyhan WL. Clinical features of the Lesch-Nyhan syndrome. Arch Intern Med 1972;130:186-92.

23. Cummings JL. Frontal-subcortical circuits and Human Behavior. Arch Neurol 1993;50:873-80.

Source of Support: Nil, Conflict of Interest: None declared. 